\title{
Mortality of Alzheimer's Disease Patients: A 10-Year Follow-up Pilot Study in Shanghai
}

\author{
Yue-Qi Zhang, Chun-Fang Wang, Gang Xu, Qian-Hua Zhao, Xin-Yi Xie, \\ Hai-Lun Cui, Ying Wang, Ru-Jing Ren, Qi-Hao Guo, Gang Wang (D)
}

ABSTRACT: Background: Identifying risk factors and mortality of individuals with Alzheimer's disease (AD) could have important implications for the clinical management of AD. Objective: This pilot study aimed to examine the overall mortality of AD patients over a 10-year surveillance period in Shanghai, China. This study is an extension of our previous investigation on mortality of neurodegenerative diseases. Methods: One hundred and thirty-two AD patients recruited from the memory clinics of two hospitals in Shanghai in 2007 were followed up until December 31, 2017 or death, representing a follow-up period of up to 10 years. Overall standardized mortality ratios (SMRs) were calculated, and predictors for survival at recruitment were estimated. Results: Sixty-seven patients had died by December 31, 2017, and the SMR at 10 years of follow-up was 1.225 (95\% confidence interval 0.944-1.563). Employing Cox's proportional hazard modeling, lower Mini-Mental State Examination score, and comorbid diabetes predicted poor survival in this cohort. Conclusion: This pilot study suggests a similar survival trend of patients with AD compared to the general population in Shanghai urban region. Poor cognitive status and comorbid diabetes had a negative impact on the survival of AD patients.

RÉSUMÉ : Taux de mortalité de patients atteints de la maladie d'Alzheimer : une étude pilote de suivi menée à Shanghai au cours d'une période de dix ans. Contexte : On le sait, le fait d'identifier les facteurs de risque et de mortalité chez des patients atteints de la maladie d'Alzheimer (MA) pourrait avoir des implications importantes en ce qui concerne leur prise en charge. Objectif: Basée sur une période de suivi de dix ans, cette étude pilote entend se pencher sur le taux global de mortalité de patients atteints de la MA qui vivent en Chine dans la ville de Shanghai. Elle constitue aussi le prolongement d'une étude précédente ayant porté sur les taux de mortalité associés à certaines maladies neurodégénératives. Méthodes : Au total, 132 patients atteints de la MA et recrutés en 2007 au sein de deux cliniques de la mémoire d'hôpitaux de Shanghai ont fait l'objet d'un suivi jusqu'au 31 décembre 2017 ou jusqu'au moment de leur décès. Nous avons tout d'abord calculé leurs taux de mortalité normalisés (TMN) ; nous avons ensuite essayé de déterminer les variables explicatives de leur survie au moment de leur recrutement. Résultats : En tout, 67 patients sont décédés avant le 31 décembre 2017 . Leur TMN au terme de notre suivi a été de 1,225 (IC $95 \%$ 0,944 -1,563). En faisant appel à la régression de Cox, il s'est avéré que des résultats plus bas au test de Folstein (ou mini-mental state examination) et la présence du diabète ont permis de prédire un faible taux de survie au sein de cette cohorte. Conclusion : En matière de taux de survie, cette étude pilote suggère donc une tendance similaire chez ces patients atteints de la MA si on les compare à la population générale de la région métropolitaine de Shanghai. À ce sujet, un état cognitif détérioré de même que la présence du diabète ont entraîné un impact négatif sur leur taux de survie.

Keywords: Alzheimer's disease, Mortality, Standardized mortality ratio, Diabetes mellitus

doi: $10.1017 /$ cjn.2019.333

Can J Neurol Sci. 2020; 47: 226-230

\section{INTRODUCTION}

The prevalence of Alzheimer's disease (AD) is growing with the aging population, especially in China, one of the biggest developing countries which now has a demographic situation where the growth of the aged population has outpaced that of the younger generation, ${ }^{1,2}$ in what can be termed "the grey society." Therefore, defining the mortality and risk factors for mortality of those with AD will help us to understand the burden of the disease and provide beneficial changes in directing patient care. However, except for some reports about the prevalence of AD in China, ${ }^{2}$ there are little standardized mortality ratio (SMR) data

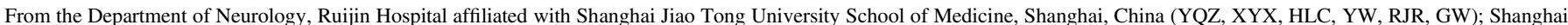

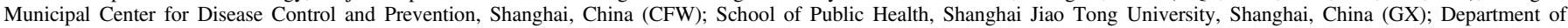

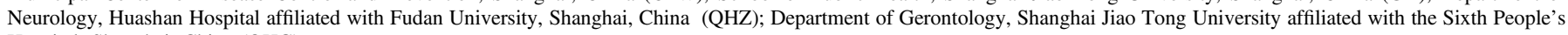
Hospital, Shanghai, China (QHG)

Received February 20, 2019. Final Revisions Submitted November 11, 2019. Date of Acceptance November 30, 2019.

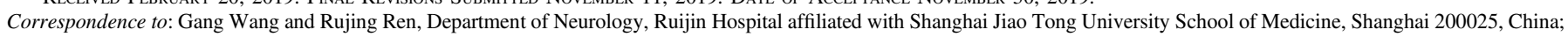

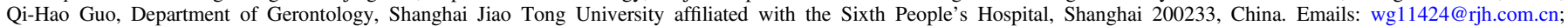
doctorren2001@126.com; qhguo@sjtu.edu.cn

Yue-Qi Zhang, Chun-Fang Wang, and Gang Xu contributed equally to this study. 
with long-term follow-up in AD patients within China in the past two decades, when there has been substantially better health care available compared to two decades prior. Therefore, the present study was modeled after previous studies ${ }^{3}$ where in $\mathrm{AD}$ patient the mortality and associated risk factors were investigated in a clinic-based cohort.

\section{Materials And Methods}

\section{Participants}

This study is of a clinic-based cohort and follows a rigorous approach to answer the critical questions of survival and causes of death in $\mathrm{AD}$. All AD patients belonging to the Chinese household registration system were recruited from the memory clinics of Rui Jin Hospital and Hua Shan Hospital by December 31, 2007 during the prior 365 days. These two hospitals accept $\mathrm{AD}$ patients referred from general practitioners, community doctors, and emergency department doctors all over the country. The memory clinics of Rui Jin Hospital affiliated with Shanghai Jiao Tong University School of Medicine and of Hua Shan Hospital affiliated with Fudan University, Shanghai, are the two biggest referral centers for $\mathrm{AD}$ diagnosis and follow-up in Shanghai, and in the entire country. Initial inclusion criteria were a diagnosis of $\mathrm{AD}$ in accordance with the NINCDS-ADRDA for $\mathrm{AD}^{4}$ Patients with mild cognitive impairment were excluded. Due to an absence of accurate information from death certificates of other provinces, patients who lived outside of the Shanghai metropolis were excluded from the present study. All participants were assessed at baseline and followed up in the clinic or community until December 31, 2017.

The study received ethical approval from the Research Ethics Committee of Rui Jin Hospital affiliated with Shanghai Jiao Tong University School of Medicine, China. Written informed consent was obtained from legal guardians of each participant.

\section{Clinical Assessment}

At baseline, researchers collected subjects' general information face to face, including demographic information, living conditions, and detailed medical history. Comorbidities, such as hypertension, diabetes mellitus (DM), and hyperlipidemia, were noted in particular. Then, all the subjects received a detailed neurological examination and underwent a psychiatric interview. The patients had a clinical diagnosis of probable dementia of Alzheimer type according to NINCDS-ADRDA. ${ }^{4}$ Age at onset of $\mathrm{AD}$ was recorded as the age when the first symptoms were perceived by the patient or family member(s). The timing of symptom onset was based primarily on the reports of clinical symptoms from the subject and/or from family members, including when they first noticed that something was amiss. Participants underwent annual follow-up, but neurocognitive tests taken at baseline were not repeated during follow-up due to their heath conditions. All data gathered were verified by senior specialists.

\section{Ascertainment of Vital Status}

As of December 31, 2017, we confirmed the vital status of all participants. For those who had died, death certificates (cause and date of death) were obtained from the database of the Shanghai Municipal Center for Disease Control and Prevention, China, which also confirmed the veracity of the information therein. Estimates of mortality based on the municipal registry provided more precise information than phone calls to family members. Diagnoses on the death certificate were registered using the International Classification of Disease tenth revision (ICD-10). Primary causes of death were grouped into different categories based on the ICD-10 classifications.

\section{Statistical Analysis}

An expected number of deaths were obtained by applying the age- and sex-specific mortality rates of the Chinese urban population in the period 2008-2017, based on the China Public Health Statistical Yearbook (2008-2017). A Kaplan-Meier survival curve was used to assess the cumulative survival rate of $\mathrm{AD}$ patients. The $t$-test or $\chi^{2}$ test was used to calculate differences between the survival group and deceased groups. Potential risk factors for death were entered into Cox's proportional hazard modeling according to the results from the $t$-test or $\chi^{2}$ test and previous reports.

All above data analyses were performed using SPSS statistical software. All $p$-values were two-tailed, and we considered $p<0.05$ as significant.

\section{Results}

\section{Sample Characteristics}

A total of $132 \mathrm{AD}$ patients were followed up in the clinic until December 31, 2017. The baseline characteristics are shown in Table 1.

\section{Mortality and Factors Related to Death}

SMR of AD patients and corresponding 95\% confidence intervals (CIs) is 1.225 (95\% CI 0.944-1.563), comparable with an age- and sex-matched Chinese urban population over the same period. Mean survival time of AD patients from time of symptom onset is 145 (95\% CI 126-164) months. Additionally, a KaplanMeier plot illustrates that type $2 \mathrm{DM}$ at $\mathrm{AD}$ presentation predicted poor survival $(p=0.01)$ (Figure 1).

Findings of the single-factor Cox regression analysis are shown in Table 2, and the concomitant type $2 \mathrm{DM}$ and the Mini-Mental State Examination (MMSE) score were factors involved in statistically significant differences between the survival group and the deceased group $(p<0.05)$.

The independent predictors of mortality during follow-up were MMSE score (hazard ratio $(\mathrm{HR})=0.950,95 \%$ CI $0.912-0.991 p=0.016)$ and concomitant type $2 \mathrm{DM}(\mathrm{HR}=1.845$ 95\% CI 1.064-3.198, $p=0.029$ ) after adjusting for age and sex, Table 3).

\section{Discussion}

In the present study, we identified a similar mortality rate (1.225, 95\% CI 0.944-1.563) for patients with AD compared to the general population over a 10-year follow-up period and also found that lower MMSE score and comorbid DM are predictors for poor survival. Although some previous studies indicated differential mortality of patients with dementia compared to the general population, ${ }^{1,5}$ our present study supports a nominally normal survival outcome despite an $\mathrm{AD}$ diagnosis during prior decade in Shanghai. 
Table 1: Baseline characteristics for survival and death in patients with AD

\begin{tabular}{l|c|c|c|c}
\hline Subjects & Total $(\boldsymbol{n}=\mathbf{1 3 2})$ & $\begin{array}{c}\text { Survival group } \\
(\boldsymbol{n}=\mathbf{6 5})\end{array}$ & $\begin{array}{c}\text { Deceased group } \\
(\boldsymbol{n}=\mathbf{6 7})\end{array}$ & $\boldsymbol{p}$-values \\
\hline Age $($ mean \pm SD) at diagnosis, years & $72.05 \pm 9.60$ & $70.38 \pm 10.10$ & $73.67 \pm 8.88$ & $0.049^{*}$ \\
\hline Age $($ mean \pm SD) at onset, years & $69.11 \pm 9.30$ & $67.55 \pm 9.80$ & $70.61 \pm 8.61$ & 0.059 \\
\hline Males, $n(\%)$ & $57(43.2)$ & $30(46.2)$ & $27(40.3)$ & 0.497 \\
\hline Education duration, $n(\%)^{\#}$ & & & & 0.575 \\
\hline$<6$ years & $10(7.6)$ & $3(4.6)$ & $7(10.4)$ & \\
\hline 6-9 years & $19(14.4)$ & $9(13.8)$ & $10(14.9)$ & \\
\hline 9-12 years & $34(25.8)$ & $20(30.8)$ & $14(20.9)$ & \\
\hline $12-16$ years & $26(19.7)$ & $13(20.0)$ & $13(19.4)$ & \\
\hline$>16$ years & $41(31.1)$ & $19(29.2)$ & $22(32.8)$ & \\
\hline Time between onset and diagnosis $($ years $)$ & $2.95 \pm 3.47$ & $2.83 \pm 3.30$ & $3.06 \pm 3.65$ & 0.706 \\
\hline Hypertension, $n(\%)$ & $47(35.6)$ & $23(35.4)$ & $24(35.8)$ & 0.958 \\
\hline Type 2 DM, $n(\%)$ & $26(19.8)$ & $7(10.8)$ & $19(28.8)$ & $0.010^{*}$ \\
\hline MMSE at recruitment $($ Mean \pm SD) & $17.53 \pm 5.44$ & $18.65 \pm 4.44$ & $16.44 \pm 6.11$ & $0.019^{*}$ \\
\hline ADL at recruitment (Mean \pm SD) & $4.43 \pm 4.53$ & $4.22 \pm 4.42$ & $4.64 \pm 4.66$ & 0.620 \\
\hline
\end{tabular}

\#The education information of two persons is missing.

Abbreviations: $\mathrm{SD}=$ standard deviation; $\mathrm{MMSE}=$ Mini-Mental State Examination; $\mathrm{ADL}=$ Activity of Daily Living Scale.

$* \mathrm{p}<0.05$.
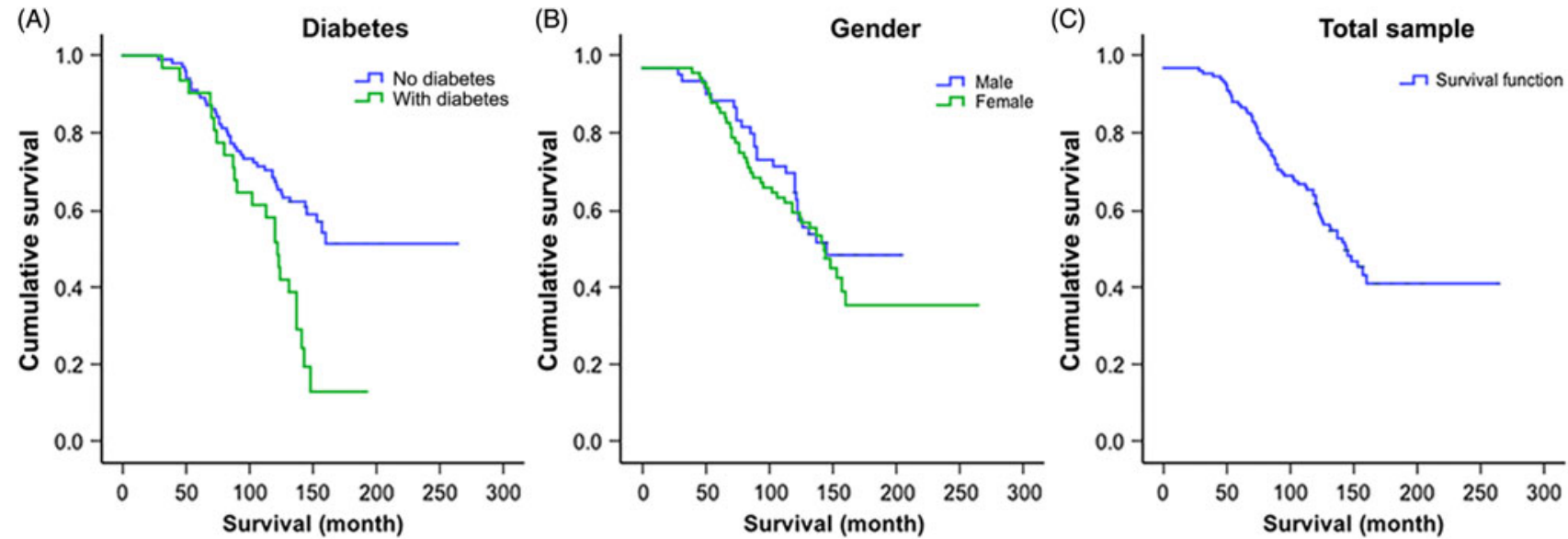

Figure 1: Survival curves using the Kaplan-Meier method. Kaplan-Meier plots illustrating the overall survival, the effect of gender, and clinical phenotype at $A D$ symptom onset and dependence on these traits of survival. (A) The survival curve of the total sample; $(B)$ the effect of gender; and $(C)$ concomitant type 2 DM effect on survival of AD patients in the cohort. Survival period begins at perceived symptom onset.

Several reasons can potentially explain why our current study demonstrates no elevated mortality for AD patients compared to various prior studies. (1) First, the diagnostic criteria used and rigorous clinical diagnosis in the present study exclude other types of dementia, such as frontotemporal dementia and vascular dementia. Indeed, according to a previous population-based study, ${ }^{6}$ non-AD dementias are associated with shorter survival and a higher risk of death than associated with AD. (2) Second, patients in this study were urban residents, a majority having a high level of education, and such persons tend to be sensitive to memory decline and to seek medical attention actively. Recently, a study by Zhou et al. ${ }^{7}$ also found that age-standardized years of life lost were significantly lower than the national mean for major causes including AD in Shanghai. Meanwhile, participants in our study are mostly from urban Shanghai. It is reasonable that patients from the urban, coastal region in eastern China generally have a better health outcome than individuals from other regions. In addition, in that population-based study, age-standardized disability-adjusted life years (DALYs) for AD and other dementias were significantly lower than expected in Shanghai in 2017, in which the ratio of observed to expected difference in DALYs was only 0.69. ${ }^{7}$ (3) Furthermore, most previous studies were conducted in the 1990s. Improved quality of care in clinical practice and better awareness of disease might play a role in the observed reduced mortality in our cohort. As practitioners, the authors indeed note that there are relatively higher levels 
Table 2: Prediction of survival in AD in single-factor Cox's proportional hazards regression model (HRs and $95 \% \mathrm{CI}$ )

\begin{tabular}{l|c|c|c}
\hline & $\boldsymbol{p}$ & HR & $\mathbf{9 5 . 0 \%}$ CI \\
\hline Age at onset & 0.100 & 1.023 & $0.996-1.051$ \\
\hline Age at diagnosis & 0.109 & 1.022 & $0.995-1.049$ \\
\hline $\begin{array}{l}\text { Time between } \\
\text { onset and } \\
\text { diagnosis }\end{array}$ & 0.984 & 1.001 & $0.932-1.075$ \\
\hline $\begin{array}{l}\text { Gender } \\
\text { female =0) }\end{array}$ & 0.451 & 0.829 & $0.508-1.350$ \\
\hline MMSE & $0.014 *$ & 0.951 & $0.913-0.990$ \\
\hline ADL & 0.678 & 1.012 & $0.958-1.069$ \\
\hline Diabetes mellitus & $0.013 *$ & 1.976 & $1.154-3.383$ \\
\hline
\end{tabular}

Abbreviations: MMSE = Mini-Mental State Examination; ADL = Activity of Daily Living Scale; $\mathrm{HR}=$ hazard radio; $\mathrm{CI}=$ confidence interval. $* \mathrm{p}<0.05$.

Table 3: Findings of the multivariate Cox regression analysis with time-dependent covariates for age and sex

\begin{tabular}{l|c|c|c}
\hline & $\boldsymbol{p}$ & HR & $\mathbf{9 5 . 0 \%}$ CI \\
\hline MMSE & $0.016^{*}$ & 0.950 & $0.912-0.991$ \\
\hline Diabetes mellitus & $0.029 *$ & 1.845 & $1.064-3.198$ \\
\hline
\end{tabular}

Abbreviations: MMSE = Mini-Mental State Examination; HR = hazard radio; $\mathrm{CI}=$ confidence interval.

$* \mathrm{p}<0.05$.

of diagnosis, treatment, and improved nursing standards for $\mathrm{AD}$ patients in Shanghai during the most recent two decades, compared with the two prior decades.

The present study confirms previous studies that found shorter survival time for individuals with $\mathrm{AD}$ and comorbid type $2 \mathrm{DM}^{8-11}$ A previous study determined that the duration of diabetes was an important modifier of dementia onset and survival. ${ }^{9}$ Moreover, a history of diabetes may be associated with a faster annual rate of cognitive decline in AD patients. ${ }^{12}$ DM seems to promote specific neuropathologic processes that contribute to dementia, concurrent with cerebral atrophy, lacunar infarcts, and white matter lesions. ${ }^{13,14}$ However, the evidence for an association between DM and cognitive decline in $\mathrm{AD}$ patients is contradicted in other studies. ${ }^{15,16}$ One hypothesis is that diabetic patients may have more frequently received cardiovascular risk-modifying medications or insulinsensitizing agents, which might contribute to a slower progression of cognitive decline in patients with AD. ${ }^{16}$ Notably, both $\mathrm{AD}$ and $\mathrm{DM}$ are chronic diseases that may share common pathologic features, ${ }^{17}$ where there is mounting evidence of brain glucose dysregulation in $\mathrm{AD} .^{18}$ In our view, insulin resistance and abnormal glucose metabolism of pre-existing type 2 DM patients may influence insulin sensitivity in brain and aggravate $\beta$-amyloid accumulation ${ }^{19}$ and, consequently, accelerate the progression of $\mathrm{AD}$.

Consistent with previous studies, lower MMSE score indicated a higher risk of death. ${ }^{10,20}$ Notably, patients with faster cognitive decline tend to have significantly lower MMSE score at the time of diagnosis of $\mathrm{AD} .^{21}$ Another cohort study on mortality risk after diagnosis of various types of dementia demonstrated an association between worse baseline cognition (as represented by MMSE) and higher risk of death. ${ }^{6}$ Interestingly, both age at onset and age at diagnosis are not associated with mortality in $\mathrm{AD}$ in our study.

In the present study, sex and education levels were not significant risk factors impacting AD patient survival. Although we presently found that $\mathrm{AD}$ increased mortality risk more significantly among women (SMRs of female AD patients are 1.593 (95\% CI 1.129-2.183)), this controversial result could be related to the fact that males in general already have an elevated mortality risk and a reduced life expectancy compared to females. For this reason, significant sex differences of survival have not been observed, although our results are consistent with a 15 -year epidemiological study. ${ }^{22}$

\section{Limitations}

Our study is one of the few mortality studies focusing on AD and, to our knowledge, is the first long-term follow-up prospective study of mortality in Chinese AD patients to date. Mortality data obtained from a national death registry are accurate and reliable. However, our study also has limitations. First, selection bias is inevitable in this clinic-based study, as community patients are different from those seeing specialists, but the survival trends for both groups have been reported to be similar. ${ }^{7}$ Additionally, the survival rate was similar for patients with $\mathrm{AD}$ compared to the general population in our study, and this may be due to insufficient follow-up time (only 10 years) and the exclusion of the oldest AD patients ( $>90$ years old) from the follow-up subjects, according to NINCDS-ADRDA criteria of AD. ${ }^{4}$ Second, our sample size is relatively small. Last, the factors associated with death reported here are values taken at baseline and do not take into account possible changes in some factors over time. Given that other cognitive scales were not used, and potential confounding variables were not measured or were measured incompletely, future prospective studies should investigate mortality with a more comprehensive cognitive evaluation and more sophisticated analytical methods and larger sample sizes.

\section{Conclusions}

This study suggests that AD patients seem to have no significant difference in survival from that of the general population in the urban region of Shanghai (based on the China Public Health Statistical database). However, poor cognitive status and comorbid diabetes are risk predictors for poor survival. Therefore, our study suggests that interventions for these risk factors should be tailored for specific AD patients.

\section{ACKNOWLEDGMENTS}

The authors would like to thank all the patients for their participation in this study.

\section{Funding}

This study was supported by grants from the National Natural Science Foundation of China (No. 81671043), the Shanghai 
Municipal Education Commission-Gaofeng Clinical Medicine Grant Support (20172001), and the "Shuguang Program (16SG15)" supported by the Shanghai Education Development Foundation and the Shanghai Municipal Education Commission.

\section{Disclosures}

All authors have no disclosures to report.

\section{Statement of Authorship}

RJR, GW, and QHG conceived and oversaw the writing; YQZ, CFW, and GX contributed to the writing; QHZ, XYX, HLC, and YW each reviewed, critiqued, and edited the manuscript.

\section{Ethics Approval and Consent}

The study received ethical approval from the Research Ethics Committee of Rui Jin Hospital affiliated with Shanghai Jiao Tong University School of Medicine, China.

\section{REFERENCES}

1. Li G, Shen YC, Chen $\mathrm{CH}$, et al. A three-year follow-up study of age-related dementia in an urban area of Beijing. Acta Psychiatr Scand. 1991;83:99.

2. Jia J, Wang F, Wei C, et al. The prevalence of dementia in urban and rural areas of China. Alzheimers Dement. 2014;10:1-9.

3. Wang G, Cheng Q, Zhang S, et al. Economic impact of dementia in developing countries: an evaluation of Alzheimer-type dementia in Shanghai, China. J Alzheimers Dis. 2008;15(1): 109-15.

4. McKhann G, Drachman D, Folstein M, et al. Clinicaldiagnosis of Alzheimer's disease: report of the NINCDS-ADRDA Work Group under the auspices of Department of Health and Human Services Task Force on Alzheimer's disease. Neurology. 1984;34(7):939-44.

5. Cereda E, Pedrolli C, Zagami A, et al. Body mass index and mortality in institutionalized elderly. J Am Med Dir Assoc. 2011;12:174-8.

6. Garciaptacek S, Farahmand B, Religa D, et al. Mortality risk after dementia diagnosis by dementia type and underlying factors: a cohort of 15,209 patients based on the Swedish Dementia Registry. J Alzheimers Dis. 2014;41:467.
7. Zhou M, Wang H, Zeng X, et al. Mortality, morbidity, and risk factors in China and its provinces, 1990-2017: a systematic analysis for the Global Burden of Disease Study 2017. Lancet. 2019;394(10204):1145-58.

8. Helzner EP, Scarmeas N, Cosentino S, et al. Survival in Alzheimer disease: a multiethnic, population-based study of incident cases. Neurology. 2008;71:1489.

9. Zilkens RR, Davis WA, Spilsbury K, et al. Earlier age of dementia onset and shorter survival times in dementia patients with diabetes. Am J Epidemiol. 2013;177:1246-54.

10. Go SM, Lee KS, Seo SW, et al. Survival of Alzheimer's disease patients in Korea. Dement Geriatr Cogn Disord. 2013;35(3-4):219-28.

11. Imfeld P, Bodmer M, Jick SS, et al. Metformin, other antidiabetic drugs, and risk of Alzheimer's disease: a population-based casecontrol study. J Am Geriatr Soc. 2012;60:916-21.

12. Helzner EP, Luchsinger JA, Scarmeas N, et al. Contribution of vascular risk factors to the progression in Alzheimer disease. Arch Neurol. 2009;66:343-8.

13. Jongen C, Grond $\mathrm{J}$ van dar, Kappelle LJ, et al. Automated measurement of brain and white matter lesion volume in type 2 diabetes mellitus. Diabetologia. 2007;50:1509-16.

14. van Harten B, de Leeuw FE, Weinstein HC, et al. Brain imaging in patients with diabetes: a systematic review. Diabetes Care. 2006;29:2539.

15. Regan C, Katona C, Walker Z, et al. Relationship of vascular risk to the progression of Alzheimer disease. Neurology. 2006;67: 1357-62.

16. Mielke MM, Rosenberg PB, Tschanz J, et al. Vascular factors predict rate of progression in Alzheimer disease. Neurology. 2007;69:1850.

17. Knowles TP, Vendruscolo M, Dobson CM. The amyloid state and its association with protein misfolding diseases. Nat Rev Mol Cell Biol. 2014;15:384-96.

18. An Y, Varma VR, Varma S, et al. Evidence for brain glucose dysregulation in Alzheimer's disease. Alzheimers Dement. 2018;14(3):318-29.

19. Han W, Li C. Linking type 2 diabetes and Alzheimer's disease. Proc Natl Acad Sci U S A. 2010;107:6557-8.

20. Zhao Q, Zhou B, Ding D, et al. Prevalence, mortality, and predictive factors on survival of dementia in Shanghai, China. Alzheimer Dis Assoc Disord. 2010;24:151-8.

21. Carcaillon L, Pérès K, Péré JJ, et al. Fast cognitive decline at the time of dementia diagnosis: a major prognostic factor for survival in the community. Dement Geriatr Cogn Disord. 2007;23:439-45.

22. Ganguli M, Dodge HH, Shen C, et al. Alzheimer disease and mortality: a 15-year epidemiological study. Arch Neurol. 2005;62:779-84. 